\title{
Engagement of Descending Inhibition from the Rostral Ventromedial Medulla Protects Against Chronic Neuropathic Pain
}

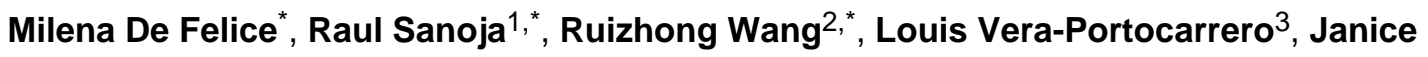 \\ Oyarzo, Tamara King, Michael H. Ossipov, Todd W. Vanderah, Josephine Lai, and Gregory \\ O. Dussor \\ Department of Pharmacology, College of Medicine, University of Arizona, Tucson, AZ, USA and \\ Howard L. Fields ${ }^{4}$ \\ Theodore J. Price ${ }^{\#}$ and Frank Porreca\# \\ ${ }^{4}$ Ernest Gallo Clinic \& Research Center, University of California San Francisco, Emeryville, CA, \\ USA
}

\begin{abstract}
A puzzling observation is why peripheral nerve injury results in chronic pain in some, but not all, patients. We explored potential mechanisms that may prevent the expression of chronic pain. Sprague-Dawley (SD) or Holtzman (HZ) rats showed no differences in baseline sensory thresholds or responses to inflammatory stimuli. However, spinal nerve ligation (SNL)-induced tactile allodynia occurred in approximately $85 \%$ of SD and $50 \%$ of $\mathrm{HZ}$ rats, respectively. No apparent differences were observed in a survey of DRG or spinal "neuropathic markers" following SNL regardless of allodynic phenotype. SNL-induced allodynia was reversed by administration of lidocaine within the rostral ventromedial medulla (RVM), a site that integrates descending pain modulation via pain inhibitory (i.e., OFF) and excitatory (i.e., ON) cells. However, in SD or HZ rats with SNL but without allodynia, RVM lidocaine precipitated allodynia. Additionally, RVM lidocaine produced conditioned place preference in allodynic SD or $\mathrm{HZ}$ rats but conditioned place aversion in non-allodynic HZ rats. Similarly, RVM U69,593 (kappa opioid agonist) or blockade of spinal $\alpha_{2}$ adrenergic receptors precipitated allodynia in previously non-allodynic $\mathrm{HZ}$ rats with SNL. All rats showed an equivalent first phase formalin responses. However, HZ rats had reduced second phase formalin behaviors along with fewer RVM OFF cell pauses and RVM ON cell bursts. Thus, expression of nerve-injury induced pain may ultimately depend on descending modulation. Engagement of descending inhibition protects in the transition from acute to chronic pain. These unexpected findings might provide a mechanistic explanation for medications that engage descending inhibition or mimic its consequences.
\end{abstract}

(C) 2011 International Association for the Study of Pain. Published by Elsevier B.V. All rights reserved.

\#Corresponding authors Frank Porreca, Ph.D. Department of Pharmacology College of Medicine University of Arizona Tucson AZ 85724 (520) 626-7421 frankp@u.arizona.edu; Theodore J. Price, Ph.D. Department of Pharmacology College of Medicine University of Arizona Tucson, AZ 85724 (520)626-4284 tjprice@email.arizona.edu .

${ }_{2}^{1}$ Department of Pharmaceutical Sciences. University of British Columbia. Vancouver BC Canada, rsanoja@interchange.ubc.ca

2 Integrative Neuroscience Section, NIDA, NIH, Baltimore, MD 21224, Ruizhong.Wang@nih.gov

3 Medtronic, Inc., Minneapolis, MN 55432 USA, louis.p.vera-portocarrero@medtronic.com

*These authors contributed equally

Publisher's Disclaimer: This is a PDF file of an unedited manuscript that has been accepted for publication. As a service to our customers we are providing this early version of the manuscript. The manuscript will undergo copyediting, typesetting, and review of the resulting proof before it is published in its final citable form. Please note that during the production process errors may be discovered which could affect the content, and all legal disclaimers that apply to the journal pertain.

None of the authors report a conflict of interest. 


\section{Introduction}

The dominant focus of research on chronic, and especially neuropathic, pain has been on changes in pain generating or transmitting mechanisms. However, many patients with peripheral nerve pathologies do not develop significant or persistent pain [55]. For example, only approximately $10 \%$ to $26 \%$ of patients with diabetes develop painful neuropathies [9; $26 ; 58$, and only $7 \%$ to $27 \%$ of patients with herpes zoster rash develop postherpetic neuralgia [31; 70]. Development of neuropathic pain after endodontic procedures [75] or traumatic nerve injury [71] occurs in less than 5\% of individuals. In spite of the considerable variability in the susceptibility of individuals to develop neuropathic pain, the reasons for this variability are unknown $[50 ; 55 ; 68]$.

One obstacle to our understanding of the variability of chronic pain resides in the animal models employed for the study of neuropathic pain. The great majority of studies of experimental neuropathic pain commonly employ rodent strains in which peripheral nerve injury consistently (i.e., >90\%) produces what appears to be a "painful" state [6]. However, some rodent strains are "resistant" to the development of experimental neuropathic pain [47; 82]. As in humans, reasons for the susceptibility and/or resistance to experimental neuropathic pain in rodents are not understood.

Much evidence suggests that the sensory experience of pain depends on descending pain modulatory circuits arising ultimately from the rostral ventromedial medulla (RVM) [16; 17]. Cells in the RVM project to the spinal dorsal horn and either enhance (i.e., ON cells) or inhibit (i.e., OFF cells) nociceptive traffic [17; 19; 74]. Following experimental nerve injury, facilitatory influences from the RVM can maintain central sensitization and expression of neuropathic pain behaviors $[4 ; 54 ; 60 ; 62]$. The clinical relevance of descending modulation is supported by the efficacy of drugs used for the treatment of neuropathic pain. Thus, number needed to treat (NNT) analyses consistently demonstrate that the most effective medications are those that engage descending pain inhibitory circuits or that mimic the consequences of descending inhibition [20]. Such compounds include tricyclic antidepressants [42; 46], serotonin-norepinephrine reuptake inhibitors (SNRI's) [36; 42] and norepinephrine (NE) reuptake blockers such as duloxetine, a compound with FDA approval for neuropathic pain, [21]. Spinal clonidine has been shown to be effective in neuropathic patients [14; 43]. Additionally, opiates are efficacious in neuropathic pain [20], and act, in part, by engagement of descending inhibition $[15 ; 17 ; 33]$. Finally, recent evidence suggests the possibility that gabapentinoids may also engage descending inhibition from the locus coeruleus $[27 ; 28]$.

We observed that two closely related outbred strains [32], Sprague-Dawley (SD) and Holtzman (HZ) rats, showed different incidences of neuropathic pain behaviors after spinal nerve ligation (SNL) injury. Rather than looking for mechanisms that promote pain, here, we took advantage of this dichotomy to explore mechanisms that might protect against the development of a chronic neuropathic pain state. Based on mechanisms of drugs effective in patients, we hypothesized that differences in the expression of experimental neuropathic pain may be a consequence of engagement of descending pain inhibitory mechanisms.

\section{METHODS}

All testing was performed in male SD or HZ (outbred) rats from the same supplier (Harlan, Indianapolis, Indiana). These are genetically homogenous outbred strains [32]. All experiments were performed in accordance with the policies of the International Association for the Study of Pain and received approval from the Institutional Animal Care and Use 
Committee (IACUC) of the University of Arizona. All behavioral testing was performed by an experimenter blinded to the surgery and to the strain.

\section{Spinal nerve ligation (SNL)}

Nerve injury to the L5 and L6 spinal nerves was performed as described by Kim and Chung [39]. Rats were anesthetized with isoflurane and the L5 and L6 spinal nerves were exposed and tightly ligated with 4-0 silk sutures. Rats with motor deficiency were excluded. Sham surgery was identical to SNL but without actual ligation.

\section{Complete Freund's Adjuvant (CFA)-induced Inflammation}

Rats received intraplantar injection of complete Freund's adjuvant (CFA) (100 $\mu$ l, s.c.; Calbiochem) into the left hindpaw. Control rats received an equivolume saline injection. Rats with CFA developed signs of inflammation that were prominent 4 days after the injection.

\section{Intrathecal catheter placement}

Rats were implanted with spinal catheters for intrathecal drug administration [81]. Animals were anesthetized with ketamine $(80 \mathrm{mg} / \mathrm{kg})$ and xylazine $(12 \mathrm{mg} / \mathrm{kg})$ and the atlantooccipital membrane was exposed and an incision was made through which $7.5 \mathrm{~cm}$ of PE-10 tubing was inserted and secured to the musculature. Any rats exhibiting motor deficiency were discarded from testing. Drug injections were performed in a volume of $5 \mu \mathrm{l}$, followed by a $1 \mu \mathrm{l}$ of air and then $9 \mu \mathrm{l}$ saline flush to clear the catheter.

\section{RVM Cannulation}

Anesthetized rats (ketamine and xylazine) were placed in a stereotaxic headholder. The skull was exposed and a pair of 26-gauge guide cannulae (1.2 $\mathrm{mm}$ apart and in a single pedestal; Plastics One Inc., Roanoke, VA) was directed toward the lateral portions of the RVM (AP-11.0 mm from bregma, $\mathrm{L} \pm 0.6 \mathrm{~mm}, \mathrm{DV}-8.5 \mathrm{~mm}$ from the base of skull). The guide cannulae were secured to the skull and a five day recovery period followed. Drug injections were performed by slowly expelling $0.5 \mu \mathrm{L}$ of solution through a 33-ga injection cannula protruding an additional $1 \mathrm{~mm}$ into fresh brain tissue.

\section{Paw withdrawal threshold}

The hindpaw withdrawal thresholds were measured by probing the plantar aspect of the hindpaw with 8 calibrated von Frey filaments (Stoelting, Wood Dale, Illinois) ( $0.41 \mathrm{~g}$ to 15 $\mathrm{g})$. Withdrawal threshold was determined by sequentially increasing and decreasing the stimulus strength and determined by a Dixon non-parametric test [6].

\section{Conditioned place pairing}

The single trial conditioned place preference protocol was performed as previously described [41] with conditioning day 10 days following SNL or sham surgeries. Starting 7 days post-SNL/sham surgery, all rats underwent a 3 day pre-conditioning period with behavior recorded on day 3 to verify no pre-conditioning chamber preference. All animals were exposed to the environment with full access to all chambers across 30 min each day. On day 3, behavior was recorded for 15 min and analyzed to verify absence of preconditioning chamber preference. The following day (day 4), rats received the appropriate control (i.e. vehicle) and immediately placed in the appropriate conditioning chamber for $30 \mathrm{~min}$. Four (4) hr later, rats received the appropriate drug treatment and immediately placed in the opposite conditioning chamber for $30 \mathrm{~min}$. Chamber pairings were counterbalanced. On test day 5, 20 hours following the afternoon pairing, rats were placed in the place preference box with access to all chambers and their behavior recorded 
for $15 \mathrm{~min}$ for analysis for chamber preference. Increased post-conditioning time spent in the drug-paired chamber, as compared to pre-conditioning time, indicates conditioned place preference (CPP). Decreased post-conditioning time spent in the drug-paired chamber, as compared to pre-conditioning time, indicates conditioned place aversion (CPA). No change between time spent in the drug paired chamber, as compared to pre-conditioning time, indicates no conditioned place preference or aversion.

\section{Immunohistochemistry}

Spinal tissue was fixed and stained according to previously reported established protocols [24; 56; 77]. Frozen lumbar $(20 \mu \mathrm{m})$ and DRG $(10 \mu \mathrm{m})$ sections were incubated with antibodies to selected markers.

The following antibodies and dilutions were employed: OX42 (mouse, 1:1,000, Sigma); GFAP (mouse, 1:5,000, Serotec, Raleigh, NC), Nav1.8 (rabbit, 1:1,000, gift of Dr. Sanja Novakovic, Roche Biosciences); Nav1.3 (rabbit, 1:1,000, Alomone Labs); ATF3 (rabbit, 1:5,000, Santa Cruz Biotechology), CGRP (rabbit, 1:40,000, Peninsula Laboratories), Substance P (rabbit, 1:10,000, Peninsula Laboratories), MOR (rabbit, 1:2,000, Neuromics), IB4 (Ab to lectin; 1:1,000, Vector Laboratories), P2X3 (rabbit, 1:5,000, Neuromics), Galanin (rabbit, 1:10,000, Peninsula), NPY (rabbit, 1:10,000, Peninsula), PKC $\gamma$ (rabbit, 1:20,000, Santa Cruz Biotechnology). Secondary antibodies were Cy3-conjugated goat antirabbit IgG (1:500, Jackson ImmunoResearch Laboratories, West Grove, Pennsylvania) or Alexa Fluor 594-conjugated goat anti-rabbit IgG (1:1,000, Molecular Probes, Eugene, OR). For IB4 histochemistry, the sections were directly incubated in FITC-conjugated lectin IB4 (1:1,000, Vector Labs, Burlingame, California). Fluorescence images of DRG and spinal cord sections were acquired with a Nikon E800 fluorescence microscope and a Hamamatsu C5810 color CCD camera and its proprietary Image Processor software (Hamatsu Photonic System, Bridgewater, NJ).

\section{Statistical Analysis}

Statistical comparisons among means within a treatment group were performed with ANOVA followed by Fisher's Least Significant Difference test. Pair-wise comparisons were made with Student's t-test. Comparisons between two treatments were performed by twofactor ANOVA. Significance was set at $\mathrm{P}<0.05$. Examination of frequency distributions for the response thresholds of $\mathrm{HZ}$ and SD rats with SNL revealed bimodal distributions, indicated by the presence of two maxima in each distribution [69]. One can be reasonably assured that two populations are present when the means represented by each maximum are separated by more than the sum of the standard deviations associated with each mean, as was the case here [69]. A conservative approach was taken here, where data points within two standard deviation units from the mean, representing $95 \%$ of the total sample, were included in the analysis of "allodynic" and "non-allodynic" animals.

For CPP experiments, data were analyzed before conditioning (baseline) and after conditioning using two-factor ANOVA (chambers vs. treatment) followed by Bonferroni test of post-conditioning compared to pre-conditioning time spent in the drug paired chamber to determine conditioned place preference (increase in post-conditioning time vs pre-conditioning time) or conditioned place aversion (decrease in post-conditioning time vs. pre-conditioning time) [41]. If significant conditioned place preference or conditioned place aversion was determined, group differences were analyzed using the difference from baseline scores, which were calculated for each rat using the formula: test time in chamber preconditioning time spent in chamber. Difference scores from baseline for the drug paired chamber between SNL and sham operated rats were analyzed using paired $t$-tests. Rats were 
tested for their response thresholds to von Frey filaments one day before and one day after the place preference experiment to confirm the presence or absence of allodynia.

\section{Electrophysiology}

Electrophysiology experiments were performed in male rats (250-300g) anesthetized with $4 \%$ isoflurane administered through a trachea cannula. Body temperature was kept at $37^{\circ} \mathrm{C}$ with a feedback controlled electric blanket (Harvard Apparatus, MA). Each rat was placed in a stereotaxic apparatus, a hole was drilled in the skull (1.5-2.5 $\mathrm{mm}$ caudal to interaural, within $0.5 \mathrm{~mm}$ of midline) and the dura mater was removed to allow placement of an electrode in the RVM. The plantar region was placed against a small fixed platform to allow access for mechanical and chemical (5\% formalin) stimuli. Responses to noxious radiant heat were measured with a tail flick unit (Ugo Basile, PA). Mechanical responses to a $100 \mathrm{~g}$ von Frey filament applied to the hindpaw or brief pinch with forceps were determined. Isoflurane concentration was adjusted (0.8-1.0\%) until discrete reflexes to noxious pinch (hindpaw) and heat (tail) could be elicited [49] but without causing spontaneous movements or signs of distress. Anesthesia was strictly regulated in order to avoid fluctuations that could affect RVM activity [5].

Extracellular recordings were obtained with tungsten electrodes (9-12 M $\Omega$, Frederick Haer, Brunswick, ME) and the signal was amplified (10k), bandpass filtered ( $300 \mathrm{~Hz}$ to $5 \mathrm{kHz}$ ) and digitized (SciWorks, Datawave, CO). Spike waveforms were monitored and stored for off-line analysis. Neuronal activity was recorded continuously for $30 \mathrm{~min}$ before the initiation of experimentation. ON-cells showed an increase and OFF-cells a decrease in activity preceding the occurrence of the tail flick $[1 ; 18$ and paw withdrawal $[5 ; 80]$ from a noxious stimulation source. Neutral cells showed no change in activity associated with withdrawals and were excluded from these experiments. Only cells that consistently responded to all stimuli were included. Neurons were isolated and characterized (ON-cell or OFF-cell), and 2 to 3 thermal noxious stimuli were applied at $5 \mathrm{~min}$ intervals, followed by s.c. injection of formalin $(50 \mu \mathrm{L}, 5 \%)$ into the hindpaw. Formalin produces a distinct biphasic excitatory response in spinal nociceptive-related neurons and RVM ON-cells along with a non-biphasic manner ongoing activity of RVM OFF-cells; these responses last around $60 \mathrm{~min}[10 ; 11]$. Thermal tests were repeated to confirm presence of ON-cell or OFF-cell activity, and the recording sites were marked with an electrolytic lesion [13; 67]. Neuronal firing was analyzed off-line (SciWorks, Datawave, $\mathrm{CO}$ ) and measured as spikes/sec with a bin size resolution equal to $1 \mathrm{sec}$. For ON-cells, the number of spontaneous bursts after formalin injection lasting for more than $10 \mathrm{sec}$ was assessed as well as their duration in sec. For OFF-cells, the number of complete pauses in firing lasting for more than $10 \mathrm{sec}$, and their duration, were assessed.

\section{Results}

The SD and $\mathrm{HZ}$ rats were evaluated for behavioral responses to innocuous tactile or noxious thermal stimuli in baseline conditions and after induction of hindpaw inflammation elicited by Complete Freund' Adjuvant (CFA). No differences were observed in baseline tactile (Fig. 1A) or thermal (Fig. 1B) thresholds. Moreover, there were no differences in either the time-course or the magnitude of CFA-induced tactile (Fig. 1A) or thermal hypersensitivity (Fig. 1B). A total of 185 male $\mathrm{HZ}$ rats and 150 male SD rats (250-300 g) were subjected to spinal nerve ligation (SNL) injury. An additional 50 rats of each strain were subjected to sham-surgery. All surgeries were performed by the same experimenter (J.O.). Response thresholds to probing the hindpaw with von Frey filaments were determined 10-14 days after surgery in a blinded fashion. A bimodal distribution of response thresholds was observed in both strains (Fig. 2A, 2B). The response thresholds observed in this experimental group of $150 \mathrm{SD}$ rats with SNL presented a mean withdrawal threshold (SD) of 3.7 (1.74 SD) $\mathrm{g}$ for 
the first distribution and a mean withdrawal threshold of $12.4(1.74, \mathrm{SD}) \mathrm{g}$ for the second distribution. These data were compared to historical data from an additional 633 rats of the same age and at the same time point with SNL performed by the same experimenter (J.O.) in our laboratory. No significant differences in the distributions of response thresholds were observed in either group of SD rats (Supplemental Figure 1) and for this reason, the data were combined and the response threshold distribution for all 783 SD rats with SNL is presented (Fig. 2A). In the SD rats, the mean (and standard deviation) of the first distribution was $3.8(1.65) \mathrm{g}$, and that of the second was $13.3(2.27) \mathrm{g}$. The same analysis was performed in $185 \mathrm{HZ}$ rats. For the $\mathrm{HZ}$ rats, the mean (and standard deviation) of the first distribution was $3.9(1.10) \mathrm{g}$ and that of the second was 13.7 (1.60) g. On this basis, rats responding at the mean of the first distribution (plus two standard deviations) or lower were defined as "allodynic" while those responding at the mean of the second distribution (minus two standard deviations) or greater were defined as "non-allodynic". No significant effects were found in sham-operated controls of either strain (data not shown). The data from the SD rats revealed a distribution of approximately $85 \%$ "allodynic" and 15\% "non-allodynic" animals in the overall sample of $783 \mathrm{SD}$ rats (Fig. 2A); if the analysis was done on the sample size of 150 SD rats, $90 \%$ were determined to be "allodynic" and $10 \%$ were "nonallodynic" (Supplemental Figure 1). Data from HZ rats showed that $51 \%$ of these rats were "allodynic" while 49\% were "non-allodynic" (Fig. 2B). Notably, the response thresholds of the "allodynic" HZ and SD rats were not significantly $(p>0.05)$ different. Likewise, the response thresholds of the "non-allodynic" SD and HZ groups also were not significantly different.

A survey of common "markers" associated with peripheral nerve injury in either the spinal cord and/or dorsal root ganglion (DRG) was performed in SD and $\mathrm{HZ}$ rats. Following SNL or sham surgery, DRG and spinal cords of allodynic SNL SD rats and non-allodynic HZ rats (or sham-operated controls for each strain) were stained for GFAP (astrocyte marker), OX42 (microglial marker), CGRP, SP, IB4, galanin, NPY, Nav1.3, Nav1.8, PKC $\gamma$, MOR, P2X3 and ATF3. Up- or down-regulation of these markers was similar to previous observations [7; $23 ; 24 ; 34 ; 51 ; 56 ; 60 ; 61 ; 76]$ and no apparent differences were observed between the two SNL groups (Supplemental Figs 2-5). No differences were observed between shams of either strain (Supplemental Figs 2-5). Hence, the "pain" phenotype of HZ rats did not appear to be related to differences in expression for these histochemical markers often associated with experimental neuropathy.

Previous studies from our laboratory have demonstrated that enhanced sensitivity to evoked stimuli in SD rats following SNL can be reversed by lidocaine-induced inactivation of the RVM, reflecting blockade of descending facilitation [4]. The role of descending facilitation was reinforced by lesion of putative pain facilitatory cells (i.e., presumably ON cells) within the RVM by lesion with dermorphin-saporin $[4 ; 60]$ suggesting that the observed lidocaine effects were likely to be relevant to descending modulation rather than affecting rostrally projecting fibers of passage. Allodynic and non-allodynic SD and HZ rats received RVM lidocaine and response thresholds to tactile stimulation were monitored. Consistent with previous observations [4], allodynic SD and HZ rats receiving RVM lidocaine showed a time-dependent reversal of response thresholds (Supplemental Fig. 6A, 6B); no effects were seen in sham-operated controls receiving RVM lidocaine. However, in non-allodynic SD and $\mathrm{HZ}$ rats, RVM administration of lidocaine produced a time-dependent precipitation of tactile allodynia (Fig. 3A,B). Injuries to peripheral nerves are believed to produce a tonic aversive state that reflects the presence of "spontaneous" (i.e., non-evoked) pain that can be unmasked through negative reinforcement $[40 ; 41 ; 52 ; 64]$. Thus, we have shown that inactivation of the RVM produces place preference in SD SNL rats with allodynia suggesting the presence of spontaneous "pain" [40; 41; 52; 64]. Allodynic and non-allodynic $\mathrm{HZ}$ rats received RVM lidocaine and place conditioning was performed. Consistent with our 
previous studies [41], RVM lidocaine produced place preference in allodynic SD rats (data not shown). Similarly, in HZ rats with SNL-induced allodynia, RVM lidocaine produced place preference (Fig 3C,D), revealing the presence of SNL-induced spontaneous pain. In non-allodynic $\mathrm{HZ}$ rats, however, RVM lidocaine produced conditioned place aversion (CPA) (Fig. 3C,D). This finding reveals the absence of a tonic aversive pain state in nonallodynic $\mathrm{HZ}$ rats consistent with the conclusion that these rats are protected from neuropathic pain.

U69,593, a kappa opioid receptor agonist was used experimentally as a research tool to inhibit the activity of RVM OFF and neutral cells without influencing ON cells [45] as previously reported and to ensure that transient precipitation of allodynia in previously nonallodynic $\mathrm{HZ}$ rats by RVM lidocaine reflected tonic descending inhibition rather than nonspecific effects on ascending fibers of passage. U69,593 had no effect in sham-operated rats or allodynic $\mathrm{HZ}$ rats, but precipitated allodynia in previously non-allodynic rats (Fig. 4A). As descending inhibition is thought to result in an increase in release or activity of norepinephrine in the spinal dorsal horn [59], allodynic and non-allodynic $\mathrm{HZ}$ rats received intrathecal (i.th.) administration of yohimbine ( $\alpha_{2}$ adrenergic antagonist) [2]. No effects were seen in sham-operated controls or in allodynic $\mathrm{HZ}$ rats. Consistent with a tonic descending inhibition-dependent protection from neuropathic pain, however, i.th. yohimbine precipitated allodynia in previously non-allodynic $\mathrm{HZ}$ rats (Fig. 4B).

We next asked if behavioral and electrophysiological responses in the RVM would be different between SD and $\mathrm{HZ}$ rats when C-fiber drive was elicited by formalin injection into the hindpaw. While $1^{\text {st }}$ phase responses to formalin injection were not different between rat strains, $2^{\text {nd }}$ phase behaviors were markedly reduced in $\mathrm{HZ}$ rats (Fig. 5A). Recordings were then made of RVM ON and OFF cells [5] between rat strains in lightly anesthetized animals to quantify potential differences in descending modulatory systems. Consistent with $1^{\text {st }}$ phase behavioral responses, ON cell bursts and OFF cell pauses evoked by initial formalin injection were not different between rat strains (Supplemental Fig. 7). In contrast, significant differences were seen in responses over the $60 \mathrm{~min}$ post-formalin recording period (Fig. 5B and $\mathrm{C}$ ), consistent with decreased $2^{\text {nd }}$ phase responses in $\mathrm{HZ}$ rats. In $\mathrm{HZ}$ rats, following the initial OFF cell pause, we observed a significant reduction in the total number, total duration and average duration of OFF cell pauses compared to SD rats (Fig. 5B, F, G and Supplemental Fig 8). Moreover, the number, total duration and average duration of ON cell bursts were significantly decreased in $\mathrm{HZ}$ rats when compared to SD rat ON cells (Fig. 5C,D,E, Supplemental Fig 8). We did not observe two populations of second phase response to formalin in this population of $\mathrm{HZ}$ rats.

\section{Discussion}

We have shown that both SD and $\mathrm{HZ}$ rats show variable expression of experimental neuropathic pain after a common injury protocol. SD and HZ rats are derived from the same SD stock [32] suggesting that observed differences in these closely related rats are likely to be the result of random genetic drift. The similarity between the strains is reflected in similar baseline responses to noxious thermal and light tactile stimuli, as well as in the timecourse of behaviors after CFA-induced peripheral inflammation. Thus, response thresholds prior to injury, or following an inflammatory stimulus, do not predict which individual animal is likely to develop chronic neuropathic pain. Likewise, it is also not clearly known what factors may influence the development of chronic pain in patients [50; 55; 68].

Initial studies in $150 \mathrm{SD}$ rats demonstrated the apparent presence of two populations with the great majority, but not all, animals showing SNL, but not sham-induced hypersensitivity. Data from these rats were combined with historical SD controls from our laboratory since 
(a) the surgeries were all performed by the same experimenter in the same manner; (b) the rats were the same approximate age from the same supplier; and (c) sensory thresholds were evaluated on approximately the same post-injury day (i.e., 10-14 days) in a blinded fashion and (d) the current and historical groups did not differ significantly in the mean responses for the allodynic and non-allodynic distributions. An analysis of more than 780 SD rats revealed two populations with the great majority (i.e., approximately $85 \%$ ) exhibiting neuropathic behaviors. The same analysis on $185 \mathrm{HZ}$ rats with SNL performed using the same protocol by the same experimenter and with thresholds measured under blinded conditions at the same time point also revealed two populations of animals but with an almost equal distribution of animals that did, or did not, show apparent neuropathic behaviors. The mean response and standard deviation of the first and second distribution did not differ significantly between SD and HZ rats. Rather, the difference was in the relative distribution between the two strains.

A survey of multiple common "markers" associated with experimental neuropathic pain in the DRG and spinal cord was performed; the data were consistent with previously results from multiple laboratories $[7 ; 23 ; 24 ; 34 ; 51 ; 56 ; 60 ; 61 ; 76]$. Thus, OX42, GFAP and NPY were upregulated in the DRG and/or spinal cord after SNL while IB4, substance P and CGRP were downregulated in the DRG and/or spinal cord $[7 ; 23 ; 24 ; 34 ; 51 ; 56 ; 60 ; 61$; 76]. However, histochemical markers of neuropathy could not distinguish allodynic phenotype of SD or $\mathrm{HZ}$ rats.

As therapy for neuropathic pain often relies on drugs that modulate descending circuits, and because previous preclinical data have suggested a critical role for descending facilitation in maintaining neuropathic states $[4 ; 22 ; 53 ; 62]$, we hypothesized that such clinical observations might be relevant preclinically to the post-SNL "pain" phenotype. As expected, RVM lidocaine did not alter response thresholds in sham-operated SD or HZ animals but reversed allodynia in SD or HZ rats with SNL. Strikingly, however, RVM lidocaine in SD or $\mathrm{HZ}$ rats with SNL that did not show neuropathic behaviors precipitated allodynia. In order to clarify whether these manipulations of descending pathways were associated with a tonic aversive state, allodynic or non-allodynic SD and $\mathrm{HZ}$ rats received RVM lidocaine and were evaluated using a conditioned place pairing paradigm. RVM lidocaine did not produce place preference or place aversion in either SD or $\mathrm{HZ}$ rats undergoing sham surgeries. In SD or $\mathrm{HZ}$ rats with allodynia, RVM lidocaine produced conditioned place preference consistent with the presence of spontaneous pain as previously reported [40; 41; 52; 64]. In HZ rats with SNL but not expressing allodynia, however, RVM lidocaine produced conditioned place aversion suggesting that blockade of descending inhibition precipitated an aversive state as would be associated with spontaneous pain. These results suggest that rats with SNL, but that do not express allodynia, may have enhanced activation of descending pain inhibitory systems from the RVM.

While it is possible that RVM lidocaine may affect fibers of passage and ascending pathways, the role of descending modulation was supported by (a) manipulations known to specifically modulate the activity of RVM cells thought to mediate facilitation and inhibition [16] and (b) blocking $\alpha$-adrenergic receptors thought to mediate the actions of norepinephrine arising from descending pathways [35; 38; 79]. RVM ON-cells increase their firing rate after application of radiant heat and just prior to the initiation of the nociceptive reflex, whereas OFF-cells pause in their activity prior to the reflex [18; 29; 63]. These neurons have spinopetal projections, and thus may exert facilitatory and inhibitory modulation of nociceptive inputs [19;74]. Activity of ON-cells has been linked to pain facilitation [37; 48], and may drive enhanced abnormal pain associated with nerve injury [25]. The ON-cells are directly inhibited by activation of $\mu$-opioid receptors [30; 57], whereas OFF-cells are inhibited by activation of $\kappa$-opioid receptors [45; 57]. RVM U69,593 
did not alter sensory thresholds in SD or HZ rats with allodynia or in sham-operated rats. However, RVM U69,593 precipitated allodynia in previously non-allodynic HZ rats. These data are consistent with a possible decrease of descending inhibition presumably by inhibiting OFF cell activity. The data are also consistent with the hypothesis that expression of pain after nerve injury is dependent upon the activity of an endogenous pain inhibitory system.

In order to test this possibility further, an adrenergic antagonist was administered spinally in allodynic and non-allodynic rats receiving SNL surgery. In addition to direct projections from the RVM, descending noradrenergic projections from supraspinal nuclei including the locus coeruleus, are believed to mediate a descending pain inhibition through spinal $\alpha_{2^{-}}$ adrenergic receptors $[3 ; 27 ; 28 ; 59]$. Spinal administration of the $\alpha_{2}$-adrenergic antagonist yohimbine had no effect on allodynic SD or HZ rats or in sham-operated animals. However, spinal yohimbine unmasked allodynia in previously non-allodynic HZ rats with SNL. This result is consistent with electrophysiologic studies that found that SNL is associated with a loss of $\alpha_{2}$-adrenoceptor mediated inhibition of deep spinal cord neurons in response to tactile stimuli [65]. As spinal yohimbine did not further alter thresholds in animals with allodynia there appears to be net facilitation in animals with allodynia. Taken, these studies suggest that descending noradrenergic inhibition blocks the expression of injury-induced pain. Although our studies emphasize noradrenergic mechanisms, RVM descending serotonergic systems may also play a role [72; 73]. Descending serotonergic projections promote neuropathic pain through spinal 5-HT3 receptors [44; 72]. Depletion of 5-HT in RVM neurons support a role of serotonergic projections to facilitate pain [78], and depletion of spinal 5-HT abolished behavioral and electrophysiologic parameters of enhanced pain in rats with SNL [66]. Additionally, it should be noted that clinically relevant mechanisms other than descending modulation may be important in neuropathic pain.

The possibility of differences in descending modulation in SD and $\mathrm{HZ}$ rats was tested further by directly driving nociceptors with formalin. No differences in behavioral responses to the first phase of formalin injection were observed in SD and $\mathrm{HZ}$ rats. However, $\mathrm{HZ}$ rats had markedly reduced nocifensive behaviors compared to SD rats in the second phase of the formalin response. The behavioral data were also consistent with the responses of RVM pain modulatory cells. Thus, ON cell bursts and OFF cell pauses evoked by initial formalin injection were not different between rat strains. However, a significant reduction in OFF cell pauses as well as of ON cell bursts was observed in HZ compared to SD rats in the 60 min period following formalin. Interestingly, like the response to CFA, we did not observe two populations of second phase response to formalin in this population of $\mathrm{HZ}$ rats. The reasons for this are not known but may have to do with the type and nature of afferent input that is generated by a sub-chronic chemical stimulus as opposed to chronic nerve injury.

Our observations indicate that engagement of descending inhibition is a critical factor that can prevent the transition from acute to chronic neuropathic pain. While multiple peripheral mechanisms [8] may contribute to the development of chronic pain, our findings raise the interesting and unexpected concept that in many individuals, despite the presence of a mechanism capable of inducing pain, countervailing modulatory influences might prevent its behavioral manifestation. Our data demonstrate that descending modulation from the RVM reduces the impact of pain generators that would produce a chronically painful situation. Thus, failure to engage descending inhibition or failure to remove a necessary descending facilitation can result in chronic neuropathic pain. The mechanisms determining whether descending inhibition is engaged following nerve injury in the same strain of rat are not known. However, once developed, neuropathic pain is commonly treated by medications that engage descending inhibition or mimic the consequences of descending inhibition by raising levels of spinal norepinephrine [12]. Our data suggest that "chronification" of pain 
may ultimately depend on descending modulation that regulates the spinal consequences of peripheral nerve injury.

\section{Supplementary Material}

Refer to Web version on PubMed Central for supplementary material.

\section{Acknowledgments}

This work was supported by NIH grants R01NS065926 (TJP) and R01NS066958 (FP).

\section{References}

[1]. Barbaro NM, Heinricher MM, Fields HL. Putative pain modulating neurons in the rostral ventral medulla: reflex- related activity predicts effects of morphine. Brain Res. 1986; 366(1-2):203210. [PubMed: 3697678]

[2]. Biaggioni, I.; Robertson, D. Adrenoceptor Antagonist Drugs. In: Katzung, BG., editor. Basic \& Clinical Pharmacology. Vol. Vol. 11e. The McGraw-Hill Companies, Inc.; 2009. http://www.accessmedicine.com/content.aspx?aID=4517493

[3]. Budai D, Harasawa I, Fields HL. Midbrain periaqueductal gray (PAG) inhibits nociceptive inputs to sacral dorsal horn nociceptive neurons through alpha2-adrenergic receptors. J Neurophysiol. 1998; 80(5):2244-2254. [PubMed: 9819240]

[4]. Burgess SE, Gardell LR, Ossipov MH, Malan TP Jr. Vanderah TW, Lai J, Porreca F. Timedependent descending facilitation from the rostral ventromedial medulla maintains, but does not initiate, neuropathic pain. J Neurosci. 2002; 22(12):5129-5136. [PubMed: 12077208]

[5]. Carlson JD, Maire JJ, Martenson ME, Heinricher MM. Sensitization of pain-modulating neurons in the rostral ventromedial medulla after peripheral nerve injury. J Neurosci. 2007; 27(48): 13222-13231. [PubMed: 18045916]

[6]. Chaplan SR, Bach FW, Pogrel JW, Chung JM, Yaksh TL. Quantitative assessment of tactile allodynia in the rat paw. J Neurosci Methods. 1994; 53(1):55-63. [PubMed: 7990513]

[7]. Coronel MF, Musolino PL, Brumovsky PR, Hokfelt T, Villar MJ. Bone marrow stromal cells attenuate injury-induced changes in galanin, NPY and NPY Y1-receptor expression after a sciatic nerve constriction. Neuropeptides. 2009; 43(2):125-132. [PubMed: 19168218]

[8]. Costigan M, Scholz J, Woolf CJ. Neuropathic pain: a maladaptive response of the nervous system to damage. Annu Rev Neurosci. 2009; 32:1-32. [PubMed: 19400724]

[9]. Daousi C, MacFarlane IA, Woodward A, Nurmikko TJ, Bundred PE, Benbow SJ. Chronic painful peripheral neuropathy in an urban community: a controlled comparison of people with and without diabetes. Diabet Med. 2004; 21(9):976-982. [PubMed: 15317601]

[10]. de Novellis V, Mariani L, Palazzo E, Vita D, Marabese I, Scafuro M, Rossi F, Maione S. Periaqueductal grey CB1 cannabinoid and metabotropic glutamate subtype 5 receptors modulate changes in rostral ventromedial medulla neuronal activities induced by subcutaneous formalin in the rat. Neuroscience. 2005; 134(1):269-281. [PubMed: 15953687]

[11]. Dickenson AH, Sullivan AF. Subcutaneous formalin-induced activity of dorsal horn neurones in the rat: differential response to an intrathecal opiate administered pre or post formalin. Pain. 1987; 30(3):349-360. [PubMed: 3670880]

[12]. Dworkin RH, O'Connor AB, Backonja M, Farrar JT, Finnerup NB, Jensen TS, Kalso EA, Loeser JD, Miaskowski C, Nurmikko TJ, Portenoy RK, Rice AS, Stacey BR, Treede RD, Turk DC, Wallace MS. Pharmacologic management of neuropathic pain: evidence-based recommendations. Pain. 2007; 132(3):237-251. [PubMed: 17920770]

[13]. Edelmayer RM, Vanderah TW, Majuta L, Zhang ET, Fioravanti B, De Felice M, Chichorro JG, Ossipov MH, King T, Lai J, Kori SH, Nelsen AC, Cannon KE, Heinricher MM, Porreca F. Medullary pain facilitating neurons mediate allodynia in headache-related pain. Ann Neurol. 2009; 65(2):184-193. [PubMed: 19259966] 
[14]. Eisenach JC, DuPen S, Dubois M, Miguel R, Allin D. Epidural clonidine analgesia for intractable cancer pain. The Epidural Clonidine Study Group. Pain. 1995; 61(3):391-399.

[15]. Fields HL. Pain modulation: expectation, opioid analgesia and virtual pain. Prog Brain Res. 2000; 122:245-253. [PubMed: 10737063]

[16]. Fields HL, Anderson SD, Clanton CH, Basbaum AI. Nucleus raphe magnus: a common mediator of opiate- and stimulus- produced analgesia. Trans Am Neurol Assoc. 1976; 101:208-210. [PubMed: 195380]

[17]. Fields, HL.; Basbaum, AI.; Heinricher, MM. Textbook of Pain. Vol. Vol. 5. Churchill Livingstone; Edinburgh: 2005. Central nervous system mechanisms of pain modulation; p. 125-142.

[18]. Fields HL, Bry J, Hentall I, Zorman G. The activity of neurons in the rostral medulla of the rat during withdrawal from noxious heat. J Neurosci. 1983; 3(12):2545-2552. [PubMed: 6317812]

[19]. Fields HL, Malick A, Burstein R. Dorsal horn projection targets of ON and OFF cells in the rostral ventromedial medulla. J Neurophysiol. 1995; 74(4):1742-1759. [PubMed: 8989409]

[20]. Finnerup NB, Sindrup SH, Jensen TS. The evidence for pharmacological treatment of neuropathic pain. Pain. 2010; 150(3):573-581. [PubMed: 20705215]

[21]. Fishbain D, Berman K, Kajdasz DK. Duloxetine for neuropathic pain based on recent clinical trials. Current pain and headache reports. 2006; 10(3):199-204. [PubMed: 18778574]

[22]. Gardell LR, Vanderah TW, Gardell SE, Wang R, Ossipov MH, Lai J, Porreca F. Enhanced evoked excitatory transmitter release in experimental neuropathy requires descending facilitation. J Neurosci. 2003; 23(23):8370-8379. [PubMed: 12967999]

[23]. Gardell LR, Wang R, Burgess SE, Ossipov MH, Vanderah TW, Malan TP Jr. Lai J, Porreca F. Sustained morphine exposure induces a spinal dynorphin-dependent enhancement of excitatory transmitter release from primary afferent fibers. J Neurosci. 2002; 22(15):6747-6755. [PubMed: 12151554]

[24]. Gardell LR, Wang R, Ehrenfels C, Ossipov MH, Rossomando AJ, Miller S, Buckley C, Cai AK, Tse A, Foley SF, Gong B, Walus L, Carmillo P, Worley D, Huang C, Engber T, Pepinsky B, Cate RL, Vanderah TW, Lai J, Sah DW, Porreca F. Multiple actions of systemic artemin in experimental neuropathy. Nat Med. 2003; 9(11):1383-1389. [PubMed: 14528299]

[25]. Goncalves L, Almeida A, Pertovaara A. Pronociceptive changes in response properties of rostroventromedial medullary neurons in a rat model of peripheral neuropathy. Eur J Neurosci. 2007; 26(8):2188-2195. [PubMed: 17892482]

[26]. Gregg EW, Sorlie P, Paulose-Ram R, Gu Q, Eberhardt MS, Wolz M, Burt V, Curtin L, Engelgau M, Geiss L. Prevalence of lower-extremity disease in the US adult population $>=40$ years of age with and without diabetes: 1999-2000 national health and nutrition examination survey. Diabetes Care. 2004; 27(7):1591-1597. [PubMed: 15220233]

[27]. Hayashida K, DeGoes S, Curry R, Eisenach JC. Gabapentin activates spinal noradrenergic activity in rats and humans and reduces hypersensitivity after surgery. Anesthesiology. 2007; 106(3):557-562. [PubMed: 17325515]

[28]. Hayashida K, Obata H, Nakajima K, Eisenach JC. Gabapentin acts within the locus coeruleus to alleviate neuropathic pain. Anesthesiology. 2008; 109(6):1077-1084. [PubMed: 19034104]

[29]. Heinricher MM, Barbaro NM, Fields HL. Putative nociceptive modulating neurons in the rostral ventromedial medulla of the rat: firing of on- and off-cells is related to nociceptive responsiveness. Somatosens Mot Res. 1989; 6(4):427-439. [PubMed: 2547275]

[30]. Heinricher MM, Morgan MM, Fields HL. Direct and indirect actions of morphine on medullary neurons that modulate nociception. Neuroscience. 1992; 48(3):533-543. [PubMed: 1603332]

[31]. Helgason S, Petursson G, Gudmundsson S, Sigurdsson JA. Prevalence of postherpetic neuralgia after a first episode of herpes zoster: prospective study with long term follow up. BMJ. 2000; 321(7264):794-796. [PubMed: 11009518]

[32]. Herrlein, hg. Handbook of Laboratory Animals. National Academy of Sciences; Washington, DC: 1954.

[33]. Hirakawa N, Tershner SA, Fields HL, Manning BH. Bi-directional changes in affective state elicited by manipulation of medullary pain-modulatory circuitry. Neuroscience. 2000; 100(4): 861-871. [PubMed: 11036220] 
[34]. Hu P, Bembrick AL, Keay KA, McLachlan EM. Immune cell involvement in dorsal root ganglia and spinal cord after chronic constriction or transection of the rat sciatic nerve. Brain Behav Immun. 2007; 21(5):599-616. [PubMed: 17187959]

[35]. Jasmin L, Boudah A, Ohara PT. Long-term effects of decreased noradrenergic central nervous system innervation on pain behavior and opioid antinociception. The Journal of comparative neurology. 2003; 460(1):38-55. [PubMed: 12687695]

[36]. Jones CK, Peters SC, Shannon HE. Efficacy of duloxetine, a potent and balanced serotonergic and noradrenergic reuptake inhibitor, in inflammatory and acute pain models in rodents. $\mathrm{J}$ Pharmacol Exp Ther. 2005; 312(2):726-732. [PubMed: 15494550]

[37]. Kaplan H, Fields HL. Hyperalgesia during acute opioid abstinence: evidence for a nociceptive facilitating function of the rostral ventromedial medulla. J Neurosci. 1991; 11(5):1433-1439. [PubMed: 2027054]

[38]. Kawasaki Y, Kumamoto E, Furue H, Yoshimura M. Alpha 2 adrenoceptor-mediated presynaptic inhibition of primary afferent glutamatergic transmission in rat substantia gelatinosa neurons. Anesthesiology. 2003; 98(3):682-689. [PubMed: 12606912]

[39]. Kim SH, Chung JM. An experimental model for peripheral neuropathy produced by segmental spinal nerve ligation in the rat. Pain. 1992; 50(3):355-363. [PubMed: 1333581]

[40]. King T, Qu C, Okun A, Mercado R, Ren J, Brion T, Lai J, Porreca F. Contribution of afferent pathways to nerve-injury induced spontaneous pain and evoked hypersensitivity. Pain. 2011 In press.

[41]. King T, Vera-Portocarrero L, Gutierrez T, Vanderah TW, Dussor G, Lai J, Fields HL, Porreca F. Unmasking the tonic-aversive state in neuropathic pain. Nat Neurosci. 2009; 12(11):1364-1366. [PubMed: 19783992]

[42]. Maizels M, McCarberg B. Antidepressants and antiepileptic drugs for chronic non-cancer pain. Am Fam Physician. 2005; 71(3):483-490. [PubMed: 15712623]

[43]. Martin TJ, Eisenach JC. Pharmacology of opioid and nonopioid analgesics in chronic pain states. The Journal of pharmacology and experimental therapeutics. 2001; 299(3):811-817. [PubMed: 11714863]

[44]. McCleane GJ, Suzuki R, Dickenson AH. Does a single intravenous injection of the 5HT3 receptor antagonist ondansetron have an analgesic effect in neuropathic pain? A double-blinded, placebo-controlled cross-over study. Anesth Analg. 2003; 97(5):1474-1478.

[45]. Meng ID, Johansen JP, Harasawa I, Fields HL. Kappa opioids inhibit physiologically identified medullary pain modulating neurons and reduce morphine antinociception. J Neurophysiol. 2005; 93(3):1138-1144. [PubMed: 15456805]

[46]. Mico JA, Ardid D, Berrocoso E, Eschalier A. Antidepressants and pain. Trends Pharmacol Sci. 2006; 27(7):348-354. [PubMed: 16762426]

[47]. Mogil JS, Wilson SG, Bon K, Lee SE, Chung K, Raber P, Pieper JO, Hain HS, Belknap JK, Hubert L, Elmer GI, Chung JM, Devor M. Heritability of nociception I: responses of 11 inbred mouse strains on 12 measures of nociception. Pain. 1999; 80(1-2):67-82. [PubMed: 10204719]

[48]. Morgan MM, Fields HL. Pronounced changes in the activity of nociceptive modulatory neurons in the rostral ventromedial medulla in response to prolonged thermal noxious stimuli. $\mathbf{J}$ Neurophysiol. 1994; 72(3):1161-1170. [PubMed: 7807201]

[49]. Morgan MM, Heinricher MM. Activity of neurons in the rostral medulla of the halothaneanesthetized rat during withdrawal from noxious heat. Brain Res. 1992; 582(1):154-158. [PubMed: 1498677]

[50]. Nicholson BD. Diagnosis and management of neuropathic pain: a balanced approach to treatment. J Am Acad Nurse Pract. 2003; 15(12 Suppl):3-9. [PubMed: 15055383]

[51]. Novakovic SD, Tzoumaka E, McGivern JG, Haraguchi M, Sangameswaran L, Gogas KR, Eglen RM, Hunter JC. Distribution of the tetrodotoxin-resistant sodium channel PN3 in rat sensory neurons in normal and neuropathic conditions. J Neurosci. 1998; 18(6):2174-2187. [PubMed: 9482802]

[52]. Okun A, DeFelice M, Eyde N, Ren J, Mercado R, King T, Porreca F. Transient inflammationinduced ongoing pain is driven by TRPV1 sensitive afferents. Molecular pain. 2011; 7:4. [PubMed: 21219650] 
[53]. Ossipov MH, Dussor GO, Porreca F. Central modulation of pain. The Journal of clinical investigation. 2010; 120(11):3779-3787. [PubMed: 21041960]

[54]. Ossipov MH, Hong Sun T, Malan P Jr. Lai J, Porreca F. Mediation of spinal nerve injury induced tactile allodynia by descending facilitatory pathways in the dorsolateral funiculus in rats. Neurosci Lett. 2000; 290(2):129-132. [PubMed: 10936694]

[55]. Ossipov MH, Porreca F. Challenges in the development of novel treatment strategies for neuropathic pain. NeuroRx. 2005; 2(4):650-661. [PubMed: 16489372]

[56]. Ossipov MH, Zhang ET, Carvajal C, Gardell L, Quirion R, Dumont Y, Lai J, Porreca F. Selective mediation of nerve injury-induced tactile hypersensitivity by neuropeptide Y. J Neurosci. 2002; 22(22):9858-9867. [PubMed: 12427842]

[57]. Pan ZZ, Tershner SA, Fields HL. Cellular mechanism for anti-analgesic action of agonists of the kappa-opioid receptor. Nature. 1997; 389(6649):382-385. [PubMed: 9311779]

[58]. Partanen J, Niskanen L, Lehtinen J, Mervaala E, Siitonen O, Uusitupa M. Natural history of peripheral neuropathy in patients with non-insulin-dependent diabetes mellitus. N Engl J Med. 1995; 333(2):89-94. [PubMed: 7777034]

[59]. Pertovaara A. Noradrenergic pain modulation. Prog Neurobiol. 2006; 80(2):53-83. [PubMed: 17030082]

[60]. Porreca F, Burgess SE, Gardell LR, Vanderah TW, Malan TP Jr. Ossipov MH, Lappi DA, Lai J. Inhibition of neuropathic pain by selective ablation of brainstem medullary cells expressing the mu-opioid receptor. J Neurosci. 2001; 21(14):5281-5288. [PubMed: 11438603]

[61]. Porreca F, Lai J, Bian D, Wegert S, Ossipov MH, Eglen RM, Kassotakis L, Novakovic S, Rabert DK, Sangameswaran L, Hunter JC. A comparison of the potential role of the tetrodotoxininsensitive sodium channels, PN3/SNS and NaN/SNS2, in rat models of chronic pain. Proc Natl Acad Sci U S A. 1999; 96(14):7640-7644. [PubMed: 10393873]

[62]. Porreca F, Ossipov MH, Gebhart GF. Chronic pain and medullary descending facilitation. Trends Neurosci. 2002; 25(6):319-325. [PubMed: 12086751]

[63]. Potrebic SB, Mason P, Fields HL. The density and distribution of serotonergic appositions onto identified neurons in the rat rostral ventromedial medulla. J Neurosci. 1995; 15(5 Pt 1):32733283. [PubMed: 7751910]

[64]. Qu C, King T, Okun A, Lai J, Fields HL, Porreca F. Lesion of the rostral anterior cingulate cortex eliminates the aversiveness of spontaneous neuropathic pain following partial or complete axotomy. Pain. 2011

[65]. Rahman W, D’Mello R, Dickenson AH. Peripheral nerve injury-induced changes in spinal alpha(2)-adrenoceptor-mediated modulation of mechanically evoked dorsal horn neuronal responses. J Pain. 2008; 9(4):350-359. [PubMed: 18226963]

[66]. Rahman W, Suzuki R, Webber M, Hunt SP, Dickenson AH. Depletion of endogenous spinal 5HT attenuates the behavioural hypersensitivity to mechanical and cooling stimuli induced by spinal nerve ligation. Pain. 2006; 123(3):264-274. [PubMed: 16644129]

[67]. Sanoja R, Tortorici V, Fernandez C, Price TJ, Cervero F. Role of RVM neurons in capsaicinevoked visceral nociception and referred hyperalgesia. Eur J Pain. 2010; 14(2):120 e121-129. [PubMed: 19443247]

[68]. Scadding, JW.; Wall, PD.; Melzack, R. Textbook of Pain. Vol. Vol. 4.. Churchill Livingstone; Edinburgh: 1999. Peripheral Neuropathies; p. 815-834.

[69]. Schilling MF, Watkins AE, Watkins W. Is human height bimodal? The American Statistician. 2002; 56(3):223-229.

[70]. Scott FT, Leedham-Green ME, Barrett-Muir WY, Hawrami K, Gallagher WJ, Johnson R, Breuer J. A study of shingles and the development of postherpetic neuralgia in East London. J Med Virol. 2003; 70(Suppl 1):S24-30. [PubMed: 12627483]

[71]. Sunderland, S. Nerves and nerve injuries. Churchill Livingstone; London: 1993.

[72]. Suzuki R, Rahman W, Rygh LJ, Webber M, Hunt SP, Dickenson AH. Spinal-supraspinal serotonergic circuits regulating neuropathic pain and its treatment with gabapentin. Pain. 2005; 117(3):292-303. [PubMed: 16150546] 
[73]. Suzuki R, Rygh LJ, Dickenson AH. Bad news from the brain: descending 5-HT pathways that control spinal pain processing. Trends Pharmacol Sci. 2004; 25(12):613-617. [PubMed: 15530638]

[74]. Vanegas H, Barbaro NM, Fields HL. Tail-Flick Related Activity in Medullospinal Neurons. Brain Research. 1984; 321(1):135-141. [PubMed: 6498509]

[75]. Vickers ER, Cousins MJ. Neuropathic orofacial pain part 1--prevalence and pathophysiology. Aust Endod J. 2000; 26(1):19-26. [PubMed: 11359293]

[76]. Wang R, Guo W, Ossipov MH, Vanderah TW, Porreca F, Lai J. Glial cell line-derived neurotrophic factor normalizes neurochemical changes in injured dorsal root ganglion neurons and prevents the expression of experimental neuropathic pain. Neuroscience. 2003; 121(3):815824. [PubMed: 14568039]

[77]. Wang R, King T, Ossipov MH, Rossomando AJ, Vanderah TW, Harvey P, Cariani P, Frank E, Sah DW, Porreca F. Persistent restoration of sensory function by immediate or delayed systemic artemin after dorsal root injury. Nat Neurosci. 2008; 11(4):488-496. [PubMed: 18344995]

[78]. Wei F, Dubner R, Zou S, Ren K, Bai G, Wei D, Guo W. Molecular depletion of descending serotonin unmasks its novel facilitatory role in the development of persistent pain. The Journal of neuroscience : the official journal of the Society for Neuroscience. 2010; 30(25):8624-8636. [PubMed: 20573908]

[79]. Wei H, Pertovaara A. Spinal and pontine alpha2-adrenoceptors have opposite effects on painrelated behavior in the neuropathic rat. European Journal of Pharmacology. 2006; 551(1-3):4149. [PubMed: 17027962]

[80]. Xu M, Bruchas MR, Ippolito DL, Gendron L, Chavkin C. Sciatic nerve ligation-induced proliferation of spinal cord astrocytes is mediated by kappa opioid activation of p38 mitogenactivated protein kinase. JNeurosci. 2007; 27(10):2570-2581. [PubMed: 17344394]

[81]. Yaksh TL, Rudy TA. Chronic catheterization of the spinal subarachnoid space. Physiology and Behavior. 1976; 17(2):1031-1036. [PubMed: 14677603]

[82]. Yoon YW, Lee DH, Lee BH, Chung K, Chung JM. Different strains and substrains of rats show different levels of neuropathic pain behaviors. Exp Brain Res. 1999; 129(2):167-171. [PubMed: 10591890] 


\section{Summary}

A rat population with variable responses to nerve injury indicated that activation of descending inhibition with a spinal noradrenergic component prevents development of neuropathic pain. 
A

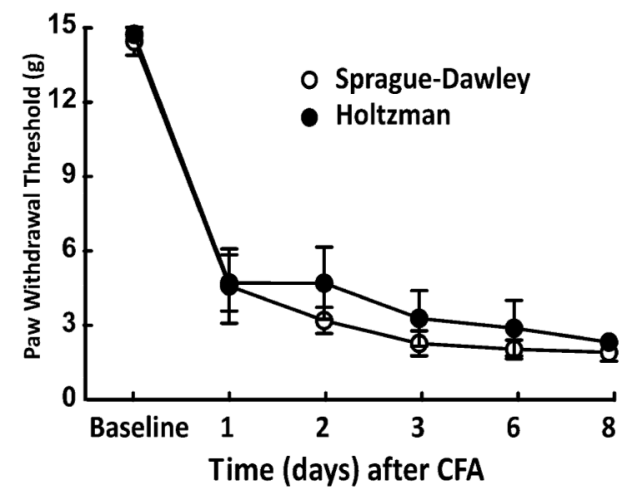

B

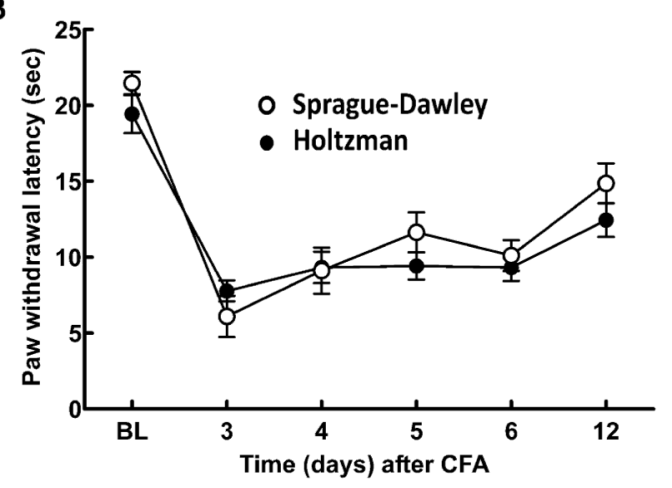

Figure 1.

Baseline mechanical thresholds are not significantly different in SD and HZ rats. Following hindpaw CFA, similar magnitude and time course of decreased tactile (A) and noxious thermal (B) thresholds are observed in both strains. 


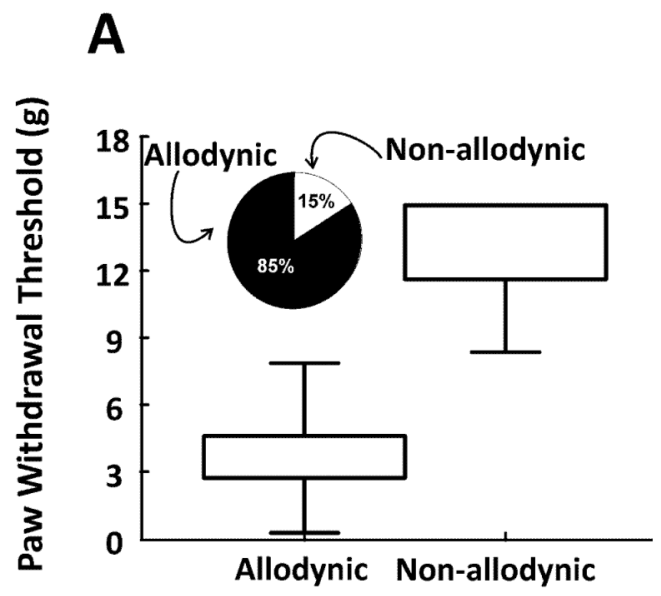

B

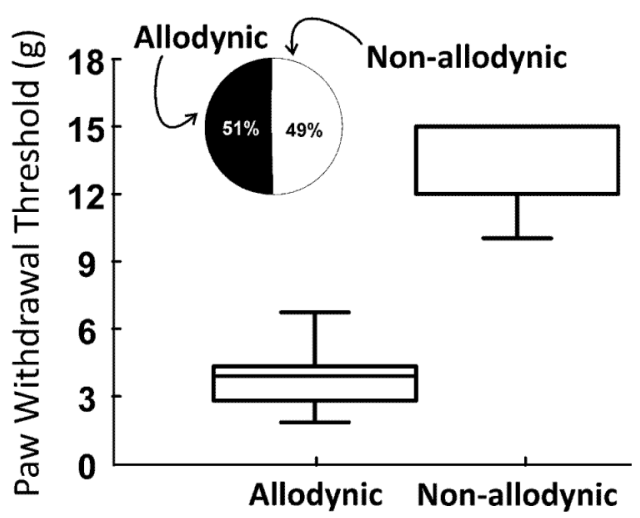

Figure 2.

A. Paw withdrawal thresholds of 783 SD rats were measured 10-14 days after SNL. Thresholds fell into a bimodal distribution, with $85 \%$ of SD rats indicating a low-threshold (allodynia) and 15\% indicating a high-threshold (non-allodynic). B. Paw withdrawal thresholds of $185 \mathrm{HZ}$ rats were measured 10-14 days after SNL. Thresholds fell into a bimodal distribution, with $51 \%$ of $\mathrm{HZ}$ rats indicating a low-threshold (allodynic) and $49 \%$ indicating a high-threshold (non-allodynic). 
A
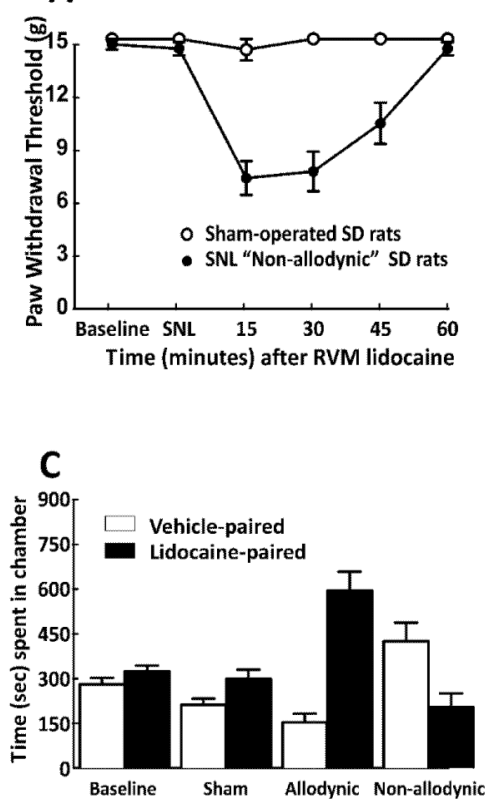
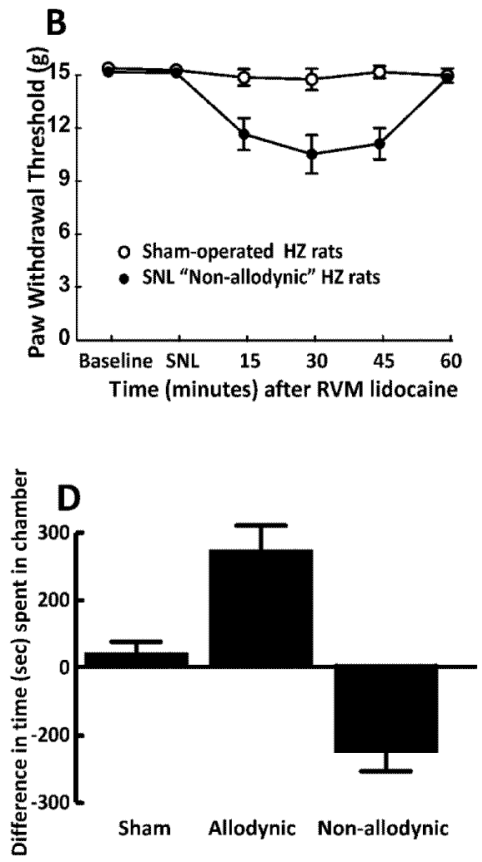

Figure 3.

$\mathrm{SD}$ (A) or $\mathrm{HZ}$ (B) rats received RVM cannula 7 days prior to SNL or sham surgery. Nonallodynic SD or $\mathrm{HZ}$ rats received lidocaine $(4 \% \mathrm{w} / \mathrm{v} ; 0.5 \mu \mathrm{l})$ in the RVM producing a transient significant $(\mathrm{p}<0.05)$ decrease in paw withdrawal thresholds indicating tactile allodynia. C. SD and $\mathrm{HZ}$ rats underwent conditioning to chambers that were paired to vehicle or lidocaine administered into the RVM. On day of testing, allodynic SD and HZ rats showed a preference (i.e., conditioned place preference) for the lidocaine-paired chamber, whereas the non-allodynic $\mathrm{HZ}$ rats showed aversion (i.e., conditioned place aversion) to the lidocaine-paired chamber. Sham-operated injected animals showed no differences from baseline. D. Data for CPP are shown as the difference in time spent in the lidocaine-paired chamber and vehicle-paired chamber. 

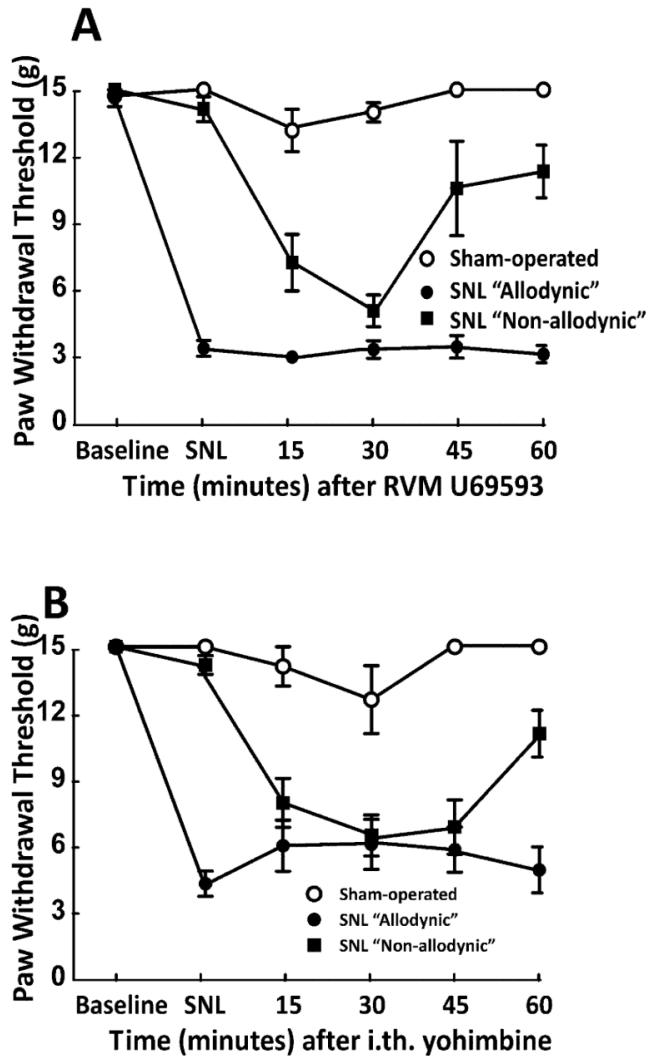

Figure 4.

A. HZ rats received sham surgery or SNL. SNL rats were separated into allodynic and nonallodynic groups and received U69593 $(1 \mu \mathrm{g})$ into the RVM. Non-allodynic HZ rats demonstrated reversible significant $(\mathrm{p}<0.05)$ decreases in paw withdrawal thresholds following RVM injection, indicating tactile allodynia. Allodynic and sham-operated $\mathrm{HZ}$ rats showed no changes from their baseline values. B. HZ rats received sham surgery or SNL. SNL rats were separated into allodynic and non-allodynic groups and received yohimbine $(30 \mu \mathrm{g})$ intrathecally. Non-allodynic HZ rats demonstrated reversible significant $(\mathrm{p}<0.05)$ decreases in paw withdrawal thresholds indicating tactile allodynia. Allodynic and shamoperated $\mathrm{HZ}$ rats showed no changes from their baseline values. 

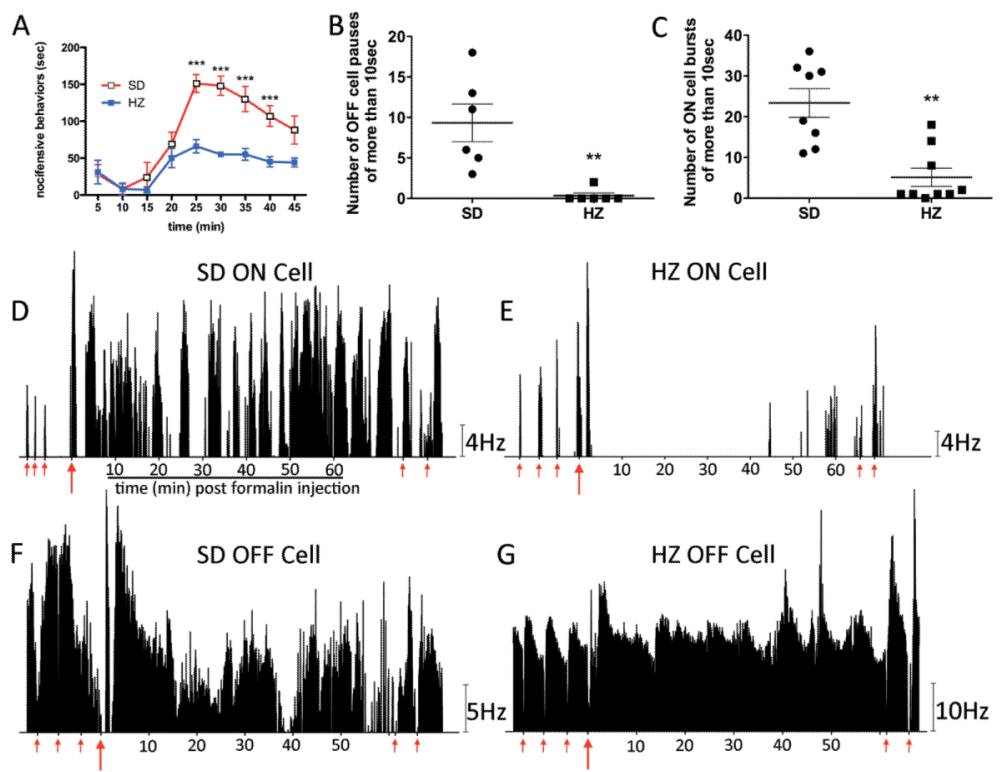

Figure 5.

C-fiber drive differentially modulates RVM ON and OFF cell activity between SD and HZ rats.

A. Behavioral responses to formalin injection into the hindpaw are shown. HZ rats showed a significant decrease in $2^{\text {nd }}$ phase behaviors compared to SD rats. The total number of OFF cell pauses $(\mathbf{B})$ and $\mathrm{ON}$ cell bursts $(\mathbf{C})$ lasting for more than $10 \mathrm{sec}$ following the initial burst and pause from formalin injection were significantly decreased in $\mathrm{HZ}$ rats compared to SD rats. Representative ratemeters for SD ON cells $(\mathbf{D})$, HZ ON cells $(\mathbf{E})$, SD OFF cells $(\mathbf{F})$ and $\mathrm{HZ}$ OFF cells $(\mathbf{G})$ demonstrate differences in RVM neuron responses to formalin injection. Small arrows indicate time of thermal stimulation of the tail paired to tail flick and RVM neuron responses. Large arrows indicate formalin injection. $* * \mathrm{p}<0.01, * * * \mathrm{p}<0.001$. 